\title{
EL INDIO REAL Y EL INDIO IDEAL: UN DILEMA EN EL ARTE ACADÉMICO MEXICANO DEL SIGLO XIX \\ Victor Ruiz Naufal*
}

Casi al concluir el año de 1892 , Leandro Izaguirre (1867-1941), entonces todavía discípulo de José Salomé Pina, dio las últimas pinceladas a un lienzo que estaba destinado a convertirse en la expresión más acabada del arte académico mexicano del siglo XIX. Se trataba de El suplicio de Cuauhtémoc, cuyo objetivo inmediato sería representar al pintor en la Exposición Internacional de Chicago, Illinois, a celebrarse en 1893. El cuadro no recibió ningún reconocimiento en los Estados Unidos, pero en México pronto se transformó en el modelo a seguir que propondrían muchos maestros y críticos. Los más insistentes fueron aquellos que pugnaban porque a la enseñanza rigurosa de las técnicas clásicas en la Academia, se sumara la sensibilidad de los artistas para resaltar los hechos cruciales de la historia mexicana y del quehacer cotidiano, a fin de utilizarlos como temas de inspiración en sus lienzos.

Cinco años antes, Miguel Noreña había logrado concretar esos ideales en la escultura, cuando llevó a cabo la efigie del último tlatoani mexica para ser colocada en una de las glorietas del Paseo de la Reforma. Por su parte, el escultor Gabriel Guerra elaboró dos paneles de bronce en bajorrelieve, que fueron integrados al pedestal del monu-

* Museo Nacional de Historia, Castillo de Chapultepec. 
mento: uno con el preciso instante en que Cuauhtémoc fue tomado como prisionero, y el otro con la representación del tormento al que fue sometido. En realidad, no se trató de una coincidencia que tanto el cuadro de Izaguirre como las esculturas de Noreña y Guerra tuvieran como motivo de inspiración al último gobernante de Tenochtitlan, pues la tragedia de su vida y el estoicismo con que afrontó la derrota eran similares a episodios vividos por muchos héroes del mundo greco-romano. En esta suerte, es posible entender que al aguerrido Cuauhtémoc se le dotara de una opulenta toga para suplir su modesta vestimenta; que se hicieran a un lado sus cactlis para que portara sandalias; que su penacho fuera sustituido por un casco emplumado, y que su ruda macana se transformara en una lanza. El color de su piel logró ser 'suavizado' con la perfección corporal de un guerrero espartano, y los rasgos indígenas 'matizados' con expresiones de arrojo y nobleza en el rostro.

La escultura de Noreña abogó por la grandeza del personaje, mientras que la pintura de Izaguirre hizo énfasis en su heroísmo y sacrificio. De acuerdo con Justino Fernández, ese cuadro "es el realismo de fin de siglo en que la Academia encontró su canto de cisne... el último gran esfuerzo del academicismo por llevar la pintura de historia a su máxima expresión, o sea, la realista reconstrucción de un hecho, de la verdad histórica misma". No obstante, el empeño por llegar a la perfección al plasmar un acontecimiento del pasado, estuvo reñido durante muchos años con la realidad mexicana. Desde su fundación en 1783 hasta mediados del siglo XIX, la Academia de San Carlos se rigió por estatutos apegados a los gustos del grupo político conservador, ya que en el mismo se encontraban sus principales mecenas. De esta manera, los alumnos fueron educados para llevar a cabo obras en las que dominaba el mensaje moral y la temática religiosa, mediante el argumento de que todo trabajo debía tener una lectura y un valor universales. Dentro de tal criterio dominaban los cánones de belleza

\footnotetext{
${ }^{1}$ Justino Fernández, Arte moderno y contemporáneo de México, 1993, México, UNAM/ Instituto de Investigaciones Estéticas, t. I, p. 140-1.
} 
de los mundos helénico y latino, así como del renacentista, a los cuales se tenía como sinónimos de una perfección que, indefectiblemente, se contraponían con la apariencia del indio sumiso, hambriento y degradado que el artista podía apreciar en sus modelos.

Y no es que se viera al pasado prehispánico como vergonzoso. Por el contrario, lo que el artista no encontraba eran sobrevivientes de esos grupos indígenas a los que tenía que representar en toda su gloria y magnificencia, tal y como se describían en los relatos de los cronistas de Indias. Quizá la idea de una edad de oro anterior a la Conquista se haya comenzado a gestar en los años inmediatos a la caída de Tenochtitlan. El antes heroico y el después degradado de los indios, ya se hacían presentes en los escritos de fray Bernardino de Sahagún y fray Diego Durán. Sin embargo, este sentimiento se volvió más profundo cuando los criollos asumieron el pasado indígena como propio y pretendieron suplir los mitos y glorias que ostentaban los nacidos en Europa con la fastuosidad del México precolombino. Empero, al ideal de la edad heroica se imponía la presencia de los indígenas sumisos, explotados y embrutecidos por los vicios. Tales sentimientos encontrados del grupo criollo, aparecieron en autores tan tempranos como Carlos de Sigüenza y Góngora, que escribió un Teatro de Virtudes Políticas para que el virrey en turno emulara la sabiduría de los antiguos gobernantes mexicanos, pero a la vez condenó a los indios y los incluyó entre la 'hez' de la sociedad cuando se levantaron en armas contra otro representante del rey.

La paradoja entre el indio histórico y el que estaba vivo y actuante, resurgió con Francisco Javier Clavijero, cuando escribió su Historia antigua de México para reivindicar el mundo que destruyó la Conquista; al tiempo en que su compañero del exilio, el jesuita Pedro José Márquez, reclamaba: "No juzgan a los antiguos sabios de Atenas, de Esparta, etcétera, considerando a los actuales habitantes de las miserables poblaciones que ocupan el lugar de aquellas célebres ciudades. Los mexicanos de ahora están destinados a hacer en la comedia del mundo, el papel de la plebe; mas sus antepasados eran educados muy 
de otra manera: tenían maestros y libros; tenían otro gobierno, y -en suma- eran los amos." 2

¿Qué había ocurrido entonces con aquel pueblo tan civilizado? Esa era la gran pregunta que se hacían los criollos y mestizos, y a la cual brindaron, como primera respuesta, el señalar a la Conquista y a los trescientos años de gobierno virreinal como los causantes de su degradación. En dicha sintonía, José María Morelos sentenció, en el discurso inaugural del Congreso de Anáhuac, que "al 12 de agosto de 1521, sucedió el 14 de septiembre de 1813. En aquél se apretaron las cadenas de nuestra servidumbre... en éste se rompen para siempre en el venturoso pueblo de Chilpancingo". ${ }^{3}$ Si embargo, pronto se hizo evidente que tal negación del pasado novohispano no llevaba implícita la reivindicación del pueblo indígena sometido. Ejemplo de ello fue la intervención de José Ignacio Rayón durante el mismo Congreso, cuando pronosticó que "la masa enorme de indios, quietos hasta ahora, y unidos con los demás americanos, [una vez] declarada la independencia, y aleccionados en la lucha, harán esfuerzos por restituir sus antiguas monarquías, como descaradamente lo pretendieron el año anterior los tlaxcaltecas en su representación al señor Morelos". ${ }^{4}$

El temor de los criollos hacia la posible insurrección indígena permaneció latente a lo largo de todo el siglo XIX y se entremezcló con propuestas que pretendían sumar a dicho grupo étnico a la modernidad. Se dijo entonces que los indios vivos habían perdido todos los elementos de su antigua cultura, que habían sido desposeídos de sus valores originales y degradados física y mentalmente. En gran medida se culpaba de este rezago a la Iglesia y a la ignorancia, por lo que se pugnó en favor de una educación que los integrara al país que se estaba

2 Pedro José Márquez, “Los mexicanos y los griegos”, en Gabriel Méndez Plancarte, Humanistas del siglo XVIII, 1991, México, UNAM, Biblioteca del Estudiante Universitario, $\mathrm{n}^{\circ} 24, \mathrm{p} .140$.

3 José María Morelos y Pavón, "Razonamiento de... en la apertura del Congreso", en El Congreso de Anáhuac. 1813, Prólogo de Manuel J. Sierra, 1963, México, Cámara de Senadores, p. 88.

${ }^{4}$ José Ignacio Rayón, “Exposición de... al Congreso”, en ibid., p. 116. 
formando y de la expedición de leyes que erradicaran los atavismos comunales, amén de dar un valor superior al individualismo y a la propiedad privada. ${ }^{5}$ En este sentido se pronunciaron ideólogos como José María Luis Mora y más tarde Guillermo Prieto; Ignacio Ramírez no estuvo de acuerdo con la idea de que el pasado glorioso se hubiera perdido para siempre y por ello abogó por crear "un establecimiento exclusivamente encargado de recopilar, explicar y publicar todos los vestigios anteriores a la Conquista de América. ¡La sabiduría nacional -puntualizaba Ramírez- debe levantarse sobre base indígena!"' ${ }^{6}$

Al igual que en el ámbito de las ideas, la ambivalencia y temores sobre los indígenas históricos y los reales estaban presentes en el campo de las artes. En realidad, la imagen del indio siempre estuvo presente en el arte virreinal y en el producido durante la primera mitad del siglo XIX. Baste tan sólo citar algunos frescos del siglo XVI, los óleos con motivos religiosos o evangelizadores, las tablas enconchadas, los biombos de la Conquista y otras pinturas con el tema de la caída de Tenochtitlan, los retratos de caciques y los cuadros de castas realizados en distintos momentos de los siglos XVII y XVIII. Por lo que toca al siglo de la Independencia, son notorias las pinturas de Rafael Ximeno y Planes tituladas El milagro del Pocito en la capilla del Palacio de Minería, y la Sublevación de los indios del Cardonal (ca. 1812-1813), realizada para el templo de Santa Teresa la Antigua. Igualmente destacados son los grabados, óleos y litografías producidos por Linati, Waldeck, Rugendas, Egerton y otros viajeros; así como los trabajos de artistas ajenos a la Academia que eran originarios de varias entidades del México independiente. Se dio incluso el caso de Juan de Dios Rodríguez Puebla, quien como director del Colegio para indios de San Gregorio, mandara edificar en el patio de ese plantel un monumento de forma piramidal, en cuyos taludes figuraban los nombres de

${ }^{5}$ Ida Rodríguez Prampolini, "La figura del indio en la pintura del siglo XIX: fondo ideológico", en La polémica del arte nacional en México, 1850-1910, compilación de Daniel Schávelzon, 1988, México, FCE, p. 207.

${ }^{6}$ Citado en ibid., p. 207. 
héroes tlaxcaltecas, mexicas, texcocanos y de indígenas participantes en la Guerra de Independencia. ${ }^{7}$

Una vez hecho este listado, conviene recalcar la presencia mayoritaria de los extranjeros en el mismo. En cambio, los pintores académicos mexicanos no comenzaron a incluir a los indios en sus obras sino hasta 1850, apenas dos años después de la firma del Tratado de Guadalupe-Hidalgo. En esa fecha Juan Cordero, estudiando en Italia, tuvo a bien plasmar a presuntos indígenas en uno de sus cuadros. El tema tratado fue Colón ante los Reyes Católicos, y como el argumento de la obra era la presentación ante los monarcas de las pruebas sobre el Nuevo Mundo descubierto, el pintor decidió incluir a tres naturales americanos en actitud reverente, aunque con rasgos marcadamente mestizos. ${ }^{8}$ Por esta obra, Juan Cordero obtuvo la distinción de pertenecer a la Congregación de Pintores Virtuosos de Roma, y casi de inmediato comenzó a ser objeto de opiniones favorables en la prensa de la Ciudad de México. Francisco Zarco, por ejemplo, sentenció:

El nombre de Cordero figurará al lado de los de Tolsá, Tresguerras, Zendejas y de cuantos han cultivado las artes en el Nuevo Mundo. Él, con sus obras, desinteresado y generoso, trabaja por la gloria de su país; y con ellas da un testimonio incontestable de que los mexicanos tienen noble inteligencia, y desmiente las preocupaciones europeas que se empeñan en creernos raza inferior al resto del mundo. ${ }^{9}$

Asimismo, en la crónica de la Exposición de San Carlos, aparecida en El Daguerrotipo del 4 de enero de 1851, se otorgó un elogio,

sincero y bien merecido al joven pintor por la finura, delicadeza y seguridad del pincel que con tanta facilidad maneja; por la bien estudiada

${ }^{7}$ Andrés Lira González, "Los indígenas y el nacionalismo mexicano", en Nacionalismo y el arte mexicano (IX Coloquio de Historia del Arte), 1986, México, UNAM/Instituto de Investigaciones Estéticas, p. 26.

${ }^{8}$ Rodríguez Prampolini, op. cit., p. 205.

9 Francisco Zarco, "Don Juan Cordero" (La Ilustración Mexicana, t. I, 1851), en Ida Rodríguez Prampolini, La crítica de arte en México en el siglo XIX, 1964, México, UNAM/ Instituto de Investigaciones Estéticas, t. I, p. 307. 
situación de los personajes, la armonía del conjunto, sus acertadas combinaciones y la expresión de los semblantes, entre los cuales son de notar los de algunos gentiles hombres y principalmente el del indio que se halla en el primer plan del lado izquierdo. El pincel del señor Cordero, al representar a ese hijo de América, se hizo sin duda el intérprete de los vivísimos recuerdos de su patria: debió entonces el pintor experimentar aquella sensación que consigo trae siempre la imagen del país natal para aquel que en lejanas regiones suspira por las delicias del suelo que lo viera nacer, en esos momentos el artista hace abstracción del ideal, y la realidad viene a estamparse en la tela bajo el impulso de la patriótica inspiración. ${ }^{10}$

Pese a ello, la 'patriótica inspiración' no tocó a otros pintores mexicanos del momento, sino nuevamente a un extranjero: el catalán Manuel Vilar. Dicho maestro de la Academia y escultor, modeló en yeso, entre 1850 y 1852, las efigies de Cristóbal Colón y de Agustín de Iturbide, así como las de Moctezuma, La Malinche y el guerrero tlaxcalteca Tlahuicole, cuya tragedia fue descrita por Clavijero en su Historia antigua de México. En tales obras, el ideal clásico se impuso a la realidad. Tanto la escultura de Moctezuma como la de La Malinche, no difieren mucho de la representación de dos bustos romanos, mientras que Tlahuicole, con toda la fuerza y dramatismo que transmite, tan sólo denuncia su ascendencia indígena por el grosor de su cabello y la raleza de su barba, mas no así por su cuerpo de centurión. Después de estas fugaces manifestaciones, el indio volvió a desaparecer del arte académico, al tiempo que las obras de Vilar corrían la suerte de ser arrumbadas en las bodegas de la Academia. ${ }^{11}$

La inestabilidad política y la sucesión de gobiernos poco hizo por las artes plásticas. Como se dijo antes, hasta 1857 la Academia estuvo patrocinada sobre todo por los grupos conservadores, que transmitieron por medio de ella su proyecto político para sacar adelante al país. El

${ }^{10}$ Anónimo, "Bellas Artes", (El Daguerrotipo, México, 4 de enero de 1851), en ibid., t. I, p. 310.

${ }^{11}$ Fernández, op. cit., t. I, p. 117-118. 
retrato dominó la época al ser visto como símbolo del prestigio social, sobre todo por la presencia en San Carlos del español Pelegrín Clavé; en segundo término se favoreció a la pintura de paisaje, impartida por el italiano Eugenio Landesio, y a la escultura regida por los patrones clásicos que difundía el propio Vilar. Todos estos maestros proclamaron que el objeto primordial de las bellas artes era 'el desarrollo de las pasiones morales', ${ }^{12}$ razón por la cual a los géneros antes mencionados se sumaron las pinturas con temas religiosos tomados de la historia sagrada, del Antiguo y Nuevo Testamentos; las imágenes de santos y de la vida conventual; las antigüedades griegas y romanas; las alegorías filosóficas, siempre que expresaran temas morales; ciertas escenas paganas; la mujer idealizada, y algunos pasajes de la historia universal. ${ }^{13}$

Los frutos de la enseñanza brindada por Clavé, Landesio y Vilar, se hicieron evidentes durante el Segundo Imperio, cuando la añeja institución educativa fue transformada en la Academia Imperial de San Carlos. Para desarrollar el discurso de la monarquía, Maximiliano prefirió asignar a artistas locales, pero formados por los maestros europeos, la ejecución de varios de sus designios más importantes. Comisionó así a Santiago Rebull la dirección del proyecto encaminado a crear, en el Palacio Nacional o Imperial, una 'Galería de Iturbide', en la cual serían colocados los retratos de los héroes de la Independencia. De esta manera, el pintor Joaquín Ramírez llevó a cabo el de Miguel Hidalgo y Costilla; Petronilo Monroy los de Morelos e Iturbide; José Obregón el de Mariano Matamoros; Ramón Sagredo el de Vicente Guerrero, y Ramón Pérez el de Ignacio Allende. ${ }^{14}$

${ }^{12}$ Esther Acevedo, Rosa E. Casanova, et. al., "El patrocinio de la Academia y la producción pictórica 1843-1857", en Las academias de arte (VII Coloquio Internacional en Guanajuato), 1985, México, UNAM/Instituto de Investigaciones Estéticas, p. 109.

${ }^{13}$ Elisa García Barragán, "El gusto a mediados del siglo XIX", en Las academias de arte..., op. cit., p. 141-2.

${ }^{14}$ Esther Acevedo, "El legado artístico de un imperio. Maximiliano en México, 18641867", en Testimonios artísticos de un episodio fugaz (1864-1867), 1995, México, Museo Nacional de Arte/Instituto Nacional de Bellas Artes/Patronato del Museo Nacional de Arte, p. 126. 
Maximiliano también se interesó en las culturas del México prehispánico. Por ello solicitó a Landesio seis paisajes históricos de asuntos anteriores a la Conquista que el maestro italiano nunca realizó, mientras que Luis Coto y José María Velasco pintaron cuadros con el mismo tema que fueron muy aclamados por la corte. El primero llevó a cabo un óleo bajo el argumento de La fundación de México y otro más con el título de Netzahualcóyotl protegido por unos indígenas en su huida. Velasco, por su parte, trazó el boceto de un cuadro con el extenso nombre de Xochitzin propone a Huauctli para jefe de los chichimecas a fin de recobrar sus dominios, usurpados por los toltecas, así como el óleo La caza, descrito en el catálogo de la exposición de 1865 como un cuadro de antiguas costumbres mexicanas. Tanto en las obras de Coto como en las de Velasco, lo dominante fue el paisaje, mientras que los asuntos del pasado indígena que pretendieron representar, tan sólo sirvieron para darle una identificación nacional al entorno. En estas obras, los indios aparecieron como seres minúsculos frente a la inmensidad de la naturaleza que los envolvía. ${ }^{15}$

Mayor presencia del indio se observó en un relieve de Miguel Noreña con el título Fray Bartolomé de las Casas convirtiendo a una familia azteca. En este trabajo, compuesto a manera de friso, el escultor reunió elementos académicos y de lapidaria indígena. De acuerdo con la investigadora Esther Acevedo, en la escena se suceden, de izquierda a derecha, motivos de índole clásica y romántica, en la representación de un indígena adulto y otro niño; reminiscencias medievales y religiosas, en las efigies de una india hincada y de fray Bartolomé armado con una cruz; así como recuerdos del México prehispánico, en un ídolo que se encuentra parcialmente cubierto por el hábito del sacerdote. En realidad, el relieve esculpido por Noreña tradujo muchas de las propuestas hechas por Manuel Vilar a sus discípulos, en el sentido mostrar en la escultura un conocimiento apasionado que,

${ }^{15}$ Ibid., p. 103-10; Fausto Ramírez, La plástica del siglo de la Independencia, 1985, México, Fondo Editorial de la Plástica Mexicana, p. 8. 
para entonces, se fundamentaba en el saber erudito de José Fernando Ramírez sobre la historia antigua de México. ${ }^{16}$

Cuando en 1867 el Imperio se vino abajo y pudo ser restaurada la República, la Academia pasó a depender directamente del Estado y se transformó en la Escuela Nacional de Bellas Artes, con el consiguiente saldo de cuentas contra los maestros y artistas que habían colaborado con el Imperio. Tal situación resulta evidente en una editorial publicada el 16 de julio de 1867 en el periódico El siglo XIX:

Con profunda pena hemos sabido que dicho establecimiento está entregado a los mismos catedráticos y empleados que lo sirvieron durante el llamado Imperio. Independientemente de lo peligroso y antilógico que es poner la instrucción pública en manos de los traidores, es además muy inmoral que sigan en sus puestos los empleados del usurpador.

La ley sólo exime de pena a los maestros de instrucción primaria; están por lo mismo comprendidos en el castigo que ella impone los catedráticos de la Academia.

Los hubo de varios establecimientos que prefirieron todo género de privaciones a servir al archiduque; que esos sean llamados a desempeñar las cátedras, y no los que adularon a su rey, y decoraron con pinturas y esculturas sus salones. ${ }^{17}$

Salvo por estas amenazas, la sangre no llegó al río; sin embargo, los nuevos tiempos obligaron a plantear como urgente necesidad la creación de una escuela de arte propia. Al igual que en 1850, cuando la invasión norteamericana reavivó la memoria de Cuauhtémoc como adalid de la resistencia, en 1867 la intervención del país por una potencia extranjera hizo voltear la mirada a las raíces más profundas del pasado mexicano. Los indígenas del tiempo heroico volvieron a resurgir como tema idóneo para ser abordado por el arte, al tiempo en que la presencia de un presidente con marcada ascendencia indígena,

${ }^{16}$ Acevedo, ibid., p. 105.

17 “Academia Nacional” (El siglo XIX, México, 16 de julio de 1867), en Rodríguez Prampolini, La crítica..., op. cit., t. II, p. 103. 
como lo era Benito Juárez, obligaba a replantear las ideas y prejuicios que se tenían acerca de los indios de ese presente.

Como ya se ha mencionado en varias ocasiones, durante la primera mitad del siglo XIX los alumnos de la Academia fueron aleccionados por maestros y críticos para hacer obras de temática religiosa o con mensajes atentos a la moral. Nada podía leerse en ellas que fuera en sentido negativo. Se trataba siempre de que los temas abordados resultaran universales, exaltadores, heroicos, gloriosos y, en última instancia, positivos. ${ }^{18}$ Pero al consolidarse la República, los críticos agregaron a esa gama temática la demanda de realizar obras en las que tuvieran un lugar preponderante los valores patrios, que muchos traicionaron al simpatizar o trabajar para el Imperio. Según advierte Ida Rodríguez Prampolini, "si los artistas se adherían a los nuevos lineamientos, se les ofrecía la oportunidad de que fueran olvidadas sus culpas como colaboracionistas. Debido a que los temas históricos no habían estado ausentes en las preferencias imperiales, el sometimiento a estas exigencias no fue dificultoso. Empero, los creadores no entendieron el mensaje que demandaba un arte capaz de reflejar la historia nacional a partir del trabajo creativo, y por ello recurrieron simplemente a los patrones neoclasicistas de la Academia francesa creados por el pintor Jacques Louis David, quien había logrado sintetizar el naturalismo y el racionalismo con un deseo de perfección". ${ }^{19}$

David plasmó en sus lienzos los grandes episodios de la historia de Grecia, Roma y Francia, a fin de ejemplificar y enaltecer los ideales republicanos, y a David se acercaron los pintores mexicanos para emular su estilo teatral y grandioso, su retórica libertaria y el uso de colores intensos. En lugar de los temas grecolatinos, en México se rescataron los pasajes de la historia prehispánica, aunque los protagonistas mostraron un físico mucho más apegado a los ideales europeos de belleza; los frontones y columnas de la arquitectura clásica eran

${ }^{18}$ Alfonso E. Pérez Sánchez, "Pintar la historia", en La pintura de historia del siglo XIX en España, 1993, Madrid, Museo del Prado, p. 32.

${ }^{19}$ Rodríguez Prampolini, "La figura del indio..., en op. cit., p. 212. 
sustituidos por puertas trapezoidales; los escalones decorados con grecas; el mobiliario formado por equipales y petates, y los cántaros y jícaras sumados a los utensilios. Las capas y túnicas romanas se transformaron en mantas, quesquemes y rebozos; las espadas en macanas, arcos y flechas, y los indios que las portaban asumieron poses y actitudes acordes con los lineamientos clasicistas. ${ }^{20}$

Para entonces, se habían producido ya varios trabajos literarios con remembranzas prehispánicas que aportarían temas de inspiración. Algunos de ellos fueron auspiciados por el equipo literario que integró la Academia de Letrán, destacando La profecía de Guatimoc (1839), poema de Ignacio Rodríguez Galván que ha sido considerado como la obra maestra del romanticismo mexicano; Anáhuac (1853), de José María Rodríguez y Cos; Los aztecas (1854), de José Joaquín Pesado, y las Leyendas mexicanas (1862), de José María Roa Bárcena. Tiempo después, fueron también los escritores y críticos liberales que publicaban en la revista El Artista, quienes con mayor empeño y contundencia incitaron a los jóvenes creadores de la Escuela de Bellas Artes a abordar temas mexicanos. Entre los más combativos se encontraba Ignacio Manuel Altamirano, a quien el pueblo veía con orgullo y como "el estimulante ejemplo del indio puro, que venciendo la gravitación del fatum se eleva y se hace célebre", según los recuerdos de José Juan Tablada. ${ }^{21}$ A mediados de la década de los setenta, Altamirano sostuvo una célebre polémica con el historiador Francisco Pimentel en torno a la literatura nacional y luego se preguntó:

¿Por qué tantos jóvenes, poseyendo un verdadero conjunto de cualidades artísticas, no han acometido la empresa de crear una escuela pictórica y escultórica esencialmente nacional, moderna y en armonía con los progresos incontrastables del siglo XIX?22

\section{${ }^{20}$ Ibidem.}

${ }^{21}$ José Juan Tablada, La feria de la vida, 1991, México, Consejo Nacional para la Cultura y las Artes, Lecturas Mexicanas, tercera serie, $n^{\circ} 22$, p. 128.

${ }^{22}$ Ignacio Manuel Altamirano, "La pintura histórica en México" (El Artista, México, 1874), en Rodríguez Prampolini. La crítica..., op. cit., t. II, p. 185. 
Por su parte, Manuel Olaguíbel aseguraba que en la pintura mexicana se había abusado del sentimiento religioso, y agregaba:

Yo no pretendo que se abandone este género, nobilísimo es, y muy grandes artistas tiene todavía que producir; pero, ¿en él existirá tan sólo la belleza?

Hay otro sentimiento, hay otro amor que es preciso cultivar, sentimiento conservador de las sociedades, amor que enaltece al individuo, el sentimiento nacional, el amor a la patria.

¡Oh! lo digo con orgullo, en muy pocas historias han de encontrarse hechos tan heroicos como en la nuestra.

Si se trata de paisaje, tampoco estamos en aquellos tiempos en que un monje visitaba la 'selva negra' y volvía desesperado diciendo que entre tanto desorden de la naturaleza no había podido encontrar asunto para un solo cuadro...

Artistas, trabajad; seréis grandes porque vuestro campo es muy extenso; para el género histórico contáis con héroes sublimes, para la pintura de interior, con tipos interesantes, y para el paisaje, con una naturaleza virgen. ${ }^{23}$

A raíz de estas interrogantes y exhortaciones, la publicación conservadora $\mathrm{La}$ Voz de México enfiló sus cañones contra ambos autores, por lo que Altamirano respondió:

Estamos en el siglo XIX y no en el siglo de la miseria y la credulidad ciega; no queremos santos ni milagros, porque ya nadie cree en esos mamarrachos sino los sacristanes, las cocottes de $L a V o z$ y los viejos imbéciles. Nuestra historia nacional es riquísima en acontecimientos dramáticos y elevados; el hogar es riquísimo en escenas de amor, de felicidad y de ternura; nuestra naturaleza con un 'horizonte de flores' como dice Manuel Olaguíbel... ¿por qué, pues, buscar modelos en una

${ }^{23}$ Manuel Olaguíbel, "Nuestros artistas. Pasado y porvenir" (El Artista, 1874), en Rodríguez Prampolini, ibid., t. II, p. 189-90. 
teogonía gastada y escrupulosa, cuando los tenemos vigorosos, fuertes y bellísimos en nuestra historia, en nuestro hogar y en nuestro suelo? ${ }^{24}$

Durante su estancia en México, el cubano José Martí agregaría:

Copien la luz en el Cinantécatl y el dolor en el rostro de Cuautemotzin; adivinen cómo se contraían los nervios de los que expiraban sobre la piedra de los sacrificios; arranquen a la fantasía los movimientos de compasión y las amargas lágrimas que ponían en el rostro de Marina el amor invencible de Cortés, y la lástima de sus míseros hermanos. Hay grandeza y originalidad en nuestra historia; haya vida original y potente en nuestra escuela de pintura. Pinte Cordero, ya que tanto ama las tintas rojas de la luz, cómo al pie de las espigas de maíz quebrantadas por los corceles del conquistador, lloraba al caer de la tarde amargamente un indio sobre la vestidura ensangrentada del hermano que pereció en la pelea, armado de piedra y lanza contra el jinete cubierto de acero, ayudado por el trueno de Dios, y favorecido todavía por los acerados dientes de un mastín. ${ }^{25}$

Un notable impulsor de este género de pintura fue el abogado, educador y político Felipe Sánchez Solís, quien de acuerdo con un boletín publicado en la Revista Universal del 17 de junio de 1875, pertenecía a "una de las más nobles familias del antiguo imperio azteca", y desde treinta años atrás había iniciado una importante colección de libros, códices y documentos que pudieran "disipar las sombras que envuelven a la historia de los pueblos que poblaron antiguamente el país". En la misma nota se advertía que Solís había hecho pintar los más notables episodios de la historia antigua, y que, para exhibirlos, había levantado un soberbio salón de arquitectura azteca. El propósito último de este liberal era crear un museo que despertara la atención sobre la raza indígena y el gusto por sus antigüedades, y al mismo

${ }^{24}$ [Ignacio Manuel Altamirano], "El Artista ante el Tribunal de la Inquisición”, ( $L a$ Tribuna, 17 de enero de 1874), en Rodríguez Prampolini, ibid., t. II, p. 219.

${ }^{25}$ José Martí, "Una visita a la Exposición de Bellas Artes", (Revista Universal, 29 de diciembre de 1875), en Rodríguez Prampolini, ibid., t. II, p. 329. 
tiempo, procurar la protección de los artistas. En el aspecto estético, aspiraba a "la formación de un arte y de una literatura realmente nacionales" mediante la creación de obras cuyas reproducciones pudieran despertar en el extranjero la curiosidad por la historia de México y el gusto por su naturaleza. ${ }^{26}$

También pretendía abrir mercados para la producción plástica mexicana con composiciones de temas localistas, cuyo tratamiento alimentara la vida nacional y diera motivos de inspiración a poetas, pintores y literatos. En otro sentido, el museo azteca representaba un espacio original y nuevo donde los amantes de las artes y las letras podrían renovar las "fuerzas bellas del espíritu humano, como cansado de alimento añejo, y ganoso de nuevos motivos de esparcimiento y solaz". En lo arqueológico, se pretendía 'resucitar una civilización' $\mathrm{y}$ "excitar el patriotismo que con los recuerdos de heroicidades y de gloria se exalta", mediante el estudio de los adelantos "que en las ciencias morales y materiales, en la legislación y en el derecho de gentes" lograron los pueblos anteriores a la llegada de Cortés, así como la restauración 'por la historia', de los monumentos y costumbres de aquellas civilizaciones, para darlos a conocer en todo el mundo. ${ }^{27}$

Los cuadros del pasado prehispánico que Solís mandó pintar expresamente para su museo fueron: El descubrimiento del pulque, de José Obregón; El senado de Tlaxcala, de Rodrigo Gutiérrez (1875); Chiconcuauhtli (1869), de Luis Coto, Cuauhtemotzin de Santiago Rebull y Netzahualcóyotl, de José Salomé Pina. En la actualidad, tan sólo se tienen noticias de los dos primeros. ${ }^{28}$ El Descubrimiento del pulque fue presentado por su autor en la exposición de la Academia correspondiente a 1869. Tradicionalmente se le considera como la pri-

${ }^{26}$ Pílades, "Boletín, reunión artística, museo de antigüedades, breve ojeada sobre ellas" (Revista Universal, 17 de junio de 1875), en Rodríguez Prampolini, La crítica..., op. cit., t. II, p. 269-71; Alfonso Sánchez Arteche, "Los motivos de un mecenas: Felipe Sánchez Solís", en Patrocinio, colección y circulación de las artes (XX Coloquio Internacional de Historia del Arte), 1997, México, UNAM/Instituto de Investigaciones Estéticas, p. 81-2.

${ }^{27}$ Sánchez Arteche, ibid., p. 82-3.

${ }^{28}$ Ibid., p. 83. 
mera pintura de tema indigenista producida con los rigores académicos, aunque además de los trabajos previos de Ximeno y Planes, Cordero, Coto y Velasco, existía el Cuauhtémoc en presencia de Cortés (1861), expuesto por Gerardo Suárez en Guadalajara. La composición de El descubrimiento del pulque es por completo neoclásica. Su apariencia es la de un friso, y el origen del tema fue una de las leyendas dadas a conocer por Roa Bárcena en 1862 bajo el título "Xóchitl o la ruina de Tula". Según ésta, Tepalcatzin, monarca de toltecas, fue justo y virtuoso hasta que Xóchitl le dio a probar el pulque y lo volvió juguete de vicios y pasiones. Así pues, su anécdota resulta moralizante y se inscribe dentro de los objetivos perseguidos por la pintura histórica elaborada en el medio académico. ${ }^{29}$ De acuerdo con un crítico, en el cuadro de Obregón "hay en suma, tanta distinción en todos los tipos, que no parece sino que el espíritu del pueblo azteca, deseando reivindicarse, guiaba el pincel del afortunado pintor". ${ }^{30}$

Por su parte, El Senado de Tlaxcala es un episodio inspirado en la novela Xicoténcatl, publicada de forma anónima en Filadelfia en 1826, aunque tampoco fue un tema que surgiera debido al azar, ya que Rodrigo Gutiérrez lo comenzó a pintar en 1874, pocos días después de que fuera restablecido el Senado de la República. En esta obra, las figuras tienen un parecido mayor con los indígenas reales. En el arrojo del rostro de Xicoténcatl, queda sintetizada la rebeldía que marcó la historia de los tlaxcaltecas, mientras que la efigie del hombre abatido que está a su derecha, prefigura con su actitud la inminencia de la derrota. $^{31}$

Un año más tarde, en la Academia fue expuesto el Fray Bartolomé de las Casas de Félix Parra. Sobre esta obra, el crítico Felipe López exclamó: "el célebre sevillano que se ha inmortalizado entre nosotros por su adhesión a la causa de los desgraciados indios, acude a un templo, derrumbado por el hierro y el fanatismo, con el loable propósito

${ }^{29}$ Ramírez, La plástica en el siglo..., op. cit., p. 75.

30 "Exposición de Bellas Artes" (El siglo XIX, 15 de noviembre de 1869), en Rodríguez Prampolini, La crítica..., op. cit., t. II, p. 143.

${ }^{31}$ Sánchez Arteche, op. cit., p. 90. 
de impedir se inmolara a un pacífico indígena... el cuerpo de la víctima necesita más estudios en la anatomía del torso y definirse mejor las extremidades inferiores; está desairado ese personaje yaciendo en completo desnudo sin accesorios que caractericen su raza". ${ }^{32}$ Por su parte, Felipe Gutiérrez prefirió no emitir una opinión sobre el mismo cuadro, sino dejar "al buen sentido de todas las personas" las apreciaciones sobre el mismo. Recogió así varios juicios:

Algunos decían que la cabeza del sacerdote no era la de su retrato, y que la fisonomía pintada, era un poco vulgar; otras decían, que un hombre como las Casas, cuyas tareas apostólicas lo obligaban a estar siempre expuesto a la intemperie, no debía tener ese color tan rozagante ni tan blanco, sino que debía ser tostado y maltratado por la fatiga; añadían otros, que la india manifestaba a través del paño de la cabeza, tener un peinado moderno, y también que estaba muy aseada. ${ }^{33}$

Como se puede observar, para esa época el idealismo de los pintores ya comenzaba a ser cuestionado, a la vez que se exigía un arte más 'realista'. La imagen del indio plasmada en dichos cuadros continuaba siendo ideal, pero comenzaba a hacerse evidente un cambio en tal criterio. De esta manera, en la exposición correspondiente a 1881 se presentaron varios trabajos de los estudiantes José María Ibarrarán, Librado Suárez, Antonio Ruiz y Alberto Briviesca sobre la Captura de Cortés en Xochimilco, tema inspirado en la Historia de la Conquista de México de William Prescott, y sobre Quetzalcóatl descubriendo el maíz, basado en la Historia de las naciones civilizadas de México de Braseur de Bourbourg. Por su parte, los alumnos de paisaje, sobre todo Carlos Rivera, mostraron trabajos con los temas El asedio de México, y Entrevista de Netzahualcóyotl y Netzahualpilli, inspirados en Clavijero, así como El mensajero del sol, pasaje extraído de fray

${ }^{32}$ Felipe López López. "Exposición de la Academia Nacional de San Carlos" (El Federalista, 10 de enero de 1876), en Rodríguez Prampolini, La crítica..., op. cit., t. II, p. 356.

${ }^{33}$ Felipe Gutiérrez, "La Exposición de Bellas Artes en 1876" (Revista Universal, 24 de febrero de 1876), en Rodríguez Prampolini, ibid., t. II, p. 379. 
Diego Durán. Por su parte, Luis Coto exhibió La captura de Guatimoc en la Laguna de Texcoco y La Noche Triste, al tiempo en que Alberto Zaffira daba a conocer un boceto relativo a Netzahualcóyotl en los jardines de Texcotzingo. Plegaria de la tarde al dios de los cielos. En la exposición correspondiente a 1886, Juan Ortega exhibió Cortés después de hacer quitar las cadenas a Moctezuma, además de Moctezuma, acompañado de sus sobrinos los príncipes de Ixtapalapan y Tlacotalpam, se adelantan... para recibir a Cortés. Este último cuadro, realizado en 1885, ofrece una composición en sesgo que evita el hieratismo, aunque en su concepción persisten las poses estatuarias propias de la retórica clásica. ${ }^{34}$

De esta enumeración se desprende que los temas recurrentes en la pintura indigenista continuaban siendo los de un glorioso pasado capaz de competir en su grandeza con el de otros 'pueblos cultos'. Dicha concepción se integraba perfectamente a la ideología de la nueva clase criolla en el poder, en la cual el indio de carne y hueso, el miserable, el hambriento y explotado, no era tomado en cuenta, salvo en contadas excepciones como la de El velorio, cuadro pintado por José Jara en 1889. Reflejo de la ausencia del indio real en el arte, resultó ser el Pabellón de México presentado en la Exposición Internacional de París del mismo año de 1889, que fue pensado y edificado por Antonio M. Anza y Antonio Peñafiel. Dicha construcción de hierro adoptó la forma de un palacio prehispánico, con un discurso escultórico en su parte frontal realizado por Jesús F. Contreras. Fausto Ramírez señala que "esta mole evocadora de los tiempos heroicos era totalmente de hierro desarmable, y en su interior se albergaban y exponían todas las manifestaciones del progreso que había traído consigo la 'pax porfiriana'. No obstante, el orgullo por el pasado indígena ocultaba la sangrienta represión que se ejercía contra los yaquis, mayos, seris y mayas, todos ellos indios irredentos que atentaban contra el proyecto modernizador". 35

${ }^{34}$ Ramírez, La plástica del siglo..., op. cit., p. 102; Fausto Ramírez, "Vertientes nacionalistas en el Modernismo", en El nacionalismo y el arte mexicano..., op. cit., p. 152-4.

${ }^{35}$ Ramírez, "Vertientes nacionalistas..., ibid., p. 156. 
Dentro de esta paradoja, la apariencia de los indios históricos en el arte se volvió cada vez más realista, dejando a un lado toda exaltación impuesta por los principios de belleza que marcaba el clasicismo de Occidente. La nueva visión se hizo presente en la XXII Exposición de Bellas Artes que se inauguró a finales de 1891. En tal ocasión, entre los temas propuestos a los alumnos de la Academia para presentar trabajos estuvo el de La fundación de México, cuyo argumento era el hallazgo, por parte de los aztecas, del águila devorando a la serpiente y posada sobre el nopal. Al llamado acudieron José Jara, Leandro Izaguirre y Joaquín Ramírez. El premio lo obtuvo Jara, mientras que Izaguirre alcanzó una mención honorífica y, según la opinión de Manuel G. Revilla, del cuadro de Ramírez lo más conveniente 'sería no hablar' ${ }^{36}$ Sobre el lienzo de Izaguirre, al que consideró el mejor, advirtió:

Las figuras del primer término podrían estar más caracterizadas y tener mayor expresión; las del segundo no están tan en esbozo y la lontananza mejor acabada... En asuntos de la elevación que nos ocupa cabe muy bien la idealización y púdose, por consiguiente, haber dado a los indios, sin desnaturalizar los rasgos distintivos de la raza, formas más bellas y carnes menos atezadas. ${ }^{37}$

Revilla sugirió con ello la posibilidad de recurrir a una nueva estética, capaz de valorar la imagen del indio por lo que era y no por lo que debería ser, aunque se pudiera acudir a algunos rasgos idealizados. En cambio, Eduardo A. Gibbons resultó contundente al postular que el arte debía sublimar al pasado, aunque tal exaltación chocara con la realidad. Así, en su crítica al cuadro ganador de José Jara, subrayó:

Un grupo de cinco figuras de indios que en su color sino en sus tipos, parecen ser Zulúes más bien que descendientes de aquella raza pura

${ }^{36}$ Manuel G. Revilla, "Exposición XXII de la Escuela Nacional de Bellas Artes (El Nacional, 13 de enero de 1892), en Rodríguez Prampolini, La crítica..., op. cit., t. III, p. 291.

${ }^{37}$ Ibid., p. 291-2. 
indígena, atlética en formas, altiva y valerosa cual los hijos de Esparta. Pero aquí en este cuadro se nota el modelo de la raza conquistada, del indio subyugado. No, ésos no pueden ser los Colhuanes aquellos cuyos hechos al decir de la historia en nada desmerecen con los de las edades más heroicas de la antigüedad. ${ }^{38}$

Mientras Gibbons escribía estas palabras, Leandro Izaguirre trabajaba en su Martirio de Cuauhtémoc, el cuadro que sería la culminación, el 'canto del cisne' del 'realismo' idealizado con que los pintores académicos abordaron el pasado indígena mexicano.

${ }^{38}$ Eduardo A. Gibbons, "Reflexiones sobre el arte nacional" (La Federación, 28 de julio de 1992), en Rodríguez Prampolini, ibid., t. III, p. 310. 